\title{
The Present Situation And Trend Analysis Of College Sport Teaching Model
}

\author{
Yue Geng ${ }^{1}$ \\ ${ }^{1}$ Taishan Medical University, Tai'an, Shandong Province, China
}

Keywords:Physical Education, Teaching Mode, Status, Trend.

\begin{abstract}
In the basic diagnosis of PE Teaching Mode Problems basis, and on the development of teaching mode for a certain dialysis tend to optimize the structure the university sports teaching mode system, to ensure that college physical education health and sustainable development.
\end{abstract}

\section{Introduction}

With the reform and development of sports teaching, defects and deficiencies PE Teaching Mode increasingly revealed, reform of college sports teaching, to get out of trouble, it should abandon the rigid discipline, curriculum, replacing development concept of development activities, the as a sports course curriculum and process activities as sports integration process, so as to create a new, vibrant sports teaching mode [1]. In Higher Education, extracurricular activities and after-school training are three basic activities, however, is undoubtedly the main course curriculum teaching college sports, two other forms are considered dispensable foil, and facts have proven that highlight the curriculum and PE teaching discipline cannot be achieved only features multiple values and functions of University Sports [1], but cause many negative effects on the physical and mental development of students, therefore, this paper analyzes the teaching mode to conduct a comprehensive study and analysis of the development trend of the theory of teaching mode.

\section{Situation Analysis of PE Teaching Model}

Traditional sports teaching in colleges and universities, not just to the students' sports habit and exercise good point of bad influence, but also to the university sports teaching curriculum and teaching patterns are adverse impact.It is because of the influence of traditional teaching framework, so at the time of sports teaching, teaching content and form, no innovation, main show is old and bloated repeat, so students in physical education in the process of nature cannot afford interest [1].Although in accordance with the education system in colleges and universities in our country a lot of reform, however, due to some it is hard to overcome the limitations, such as sports venues and equipment, teacher resources, etc., so although led directly to the articles of association during the reform in new much more suitable for the activities of the university sports teaching content, but is limited by such as above, so difficult to blend in the sports teaching of reality.

Physical education content from reality.Although China has been advocating accelerate the reform of education in colleges of various disciplines, but with little success in many ways. For example, in our traditional sports teaching mode, the main advocate of teaching is student-centered, which is generally in favor of the classroom to teach students knowledge related to sports and sports technology and thought that as long as the student's physical fitness Even the increase in Physical Education received the results; but this practice of traditional education is seriously neglected sports habits for college students, as well as the ability to develop sports consciousness. Physical education students learned only from the sports action for imitation, but have not been able to go in-depth understanding of the sport inherent deep meaning [1]. So the results caused by the traditional teaching philosophy is unable to train students on the importance of sports and hobbies, thus, remove 45 minutes of classroom time, other times not to select students basic exercise. Although China's educational reform has been on this issue put forward some solution to the problem, but the lasting influence of traditional teaching in their daily physical education is still more or less manifested, 
therefore, in many colleges and universities in our country, can be found, the student basically we do not attach importance to physical education, although in the short term, for contempt of Physical Education does not produce results too seriously, however, until the students into the community, when deteriorating physical condition, this flaw exposed.

PE teaching quality evaluation deviation.Physical Education Teaching Evaluation of Physical Education is an important part of the process, it has two main purposes: First, check the teacher's teaching situation, to help teachers identify problems, improve teaching methods, improve teaching quality [2]. The second is to enable students to understand their own learning and the need to improve at some stage, on this basis, further improve learning outcomes. But in practice, there is often the practice for the evaluation and the evaluation, the evaluation as a treatment goal of Physical Education to Comment on "standard" pursuit of short term profits, replacing the comment "teaching", the commentary "learning" vision standard to evaluate Bring a strong utilitarian. Examination or other assessment procedures used to each student in the education system of the value and future decisions, especially in some critical and often irreversible decisions. These decisions and division level often affect a student's entire career. Studies have shown that students allocated on proportional nature of the learning time and learning forces, often with the syllabus of teaching objectives, plans. So, that kind of utilitarian bias Physical Education Teaching Evaluation in understanding the teaching process leading to technical, not only reduces the interest of student learning, is not conducive to the cultivation of students' ability to generate "completion - finished - finished forgotten," the disadvantages of addiction, but due to the lag effect of feedback also restricted the teaching level, resulting in decline in the quality of teaching, teaching evaluation function weakened [2].

Physical education teaching mode unrealistic.Traditional physical education colleges and universities, not only to develop the habit of exercise and poor impact adversely impact on good ideas, but also on college physical education curriculum and teaching modes produce student sports. Because of the traditional teaching framework process precisely, and conducting sports teaching, whether it is taught in content or form, no innovation, mainly for old and bloated repeat, so students cannot naturally during physical education mention affordable interest [2]. Although the education system in accordance with the country's universities were a lot of reform, however, it is difficult to overcome because of some restrictions, such as aspects of sports venues and equipment, teacher resources, and so on, although a direct result of the reform of the new constitution mark a lot more suitable for college physical education activities, but subject to restrictions such as the above, and thus more difficult to integrate into the reality of the physical education teaching [3]. Moreover, since the traditional sports teaching basic discipline is called teaching, rather than to students interested in sports, so, even after the reform, by the influence of traditional teaching, sports teaching mode is still carried emphasis on indoctrination, and failed to reflect the reforms advocated student-centered, students interest in learning. Overtime, students are getting bored of this discipline.

\section{The countermeasures to resolve the status quo problem}

In the sports teaching in colleges and universities highlights many problems, the basic it is thanks to the school to do not pay enough attention to the management of the sports teaching.So, now that choose to thoroughly solve the problem, then you have to face the problem of colleges and universities sports teaching management directly, only solved the problem of the management, in the sports teaching can be effectively solve the problems [3].But the management of the sports teaching in colleges and universities is relatively complex, contains a lot of content, such as related to the teaching plan management, the quality of teaching management, archives, and order management and so on several aspects, so it requires the staff involved in the management of their own to have a high enough quality and technology, to can easily solve the problems in the process of teaching, also need to adapt to the teaching conditions, guarantee the smooth development in colleges and universities sports teaching.Also only can be fully competent management work, to make sports teaching in colleges and universities in the construction of health environment smoothly, to expect to achieve the goal of education reform. 
Since to be related to innovation of physical education teaching, should not be confined to the gym to build the framework of aspect, but also make the necessary innovation in teaching mode [4]. For the construction of physical education teaching framework, should it as the basis of physical education, to carry out, under the premise, systematic, scientific, global framework to build together; And on the basis of the guarantee teaching purpose at the same time, should also join the characteristics of different style, such as setting up some of the more unusual sports, such as billiards, bowling, and activities such as rock climbing and obstacle; For teaching mode innovation, is to first of all, the advantages and disadvantages of the traditional sports teaching in colleges and universities were analyzed, and clear the students what they want, hate what, what should the students to learn, to keep pace with The Times, to ensure that the lectures to help students in physical education, at the same time, still can feel physical education is a kind of fun, let the students in physical education, cultivation of sports in the student life gradually.

\section{Trend Analysis of PE Teaching Model}

Strengthen the management of physical education teaching in colleges and universities. In the sports teaching in colleges and universities highlights many problems, the basic it is thanks to the school to do not pay enough attention to the management of the sports teaching.So, now that choose to thoroughly solve the problem, then you have to face the problem of colleges and universities sports teaching management directly, only solved the problem of the management, in the sports teaching can be effectively solve the problems [4].But the management of the sports teaching in colleges and universities is relatively complex, contains a lot of content, such as related to the teaching plan management, the quality of teaching management, archives, and order management and so on several aspects, so it requires the staff involved in the management of their own to have a high enough quality and technology, to can easily solve the problems in the process of teaching, also need to adapt to the teaching conditions, guarantee the smooth development in colleges and universities sports teaching.Also only can be fully competent management work, to make sports teaching in colleges and universities in the construction of health environment smoothly, to expect to achieve the goal of education reform.

Strengthen the sports teaching and teaching mode innovation. Since to be related to innovation of physical education teaching, should not be confined to the gym to build the framework of aspect, but also make the necessary innovation in teaching mode [5].For the construction of physical education teaching framework, should it as the basis of physical education, to carry out, under the premise, systematic, scientific, global framework to build together;And on the basis of the guarantee teaching purpose at the same time, should also join the characteristics of different style, such as setting up some of the more unusual sports, such as billiards, bowling, and activities such as rock climbing and obstacle;For teaching mode innovation, is to first of all, the advantages and disadvantages of the traditional sports teaching in colleges and universities were analyzed, and clear the students what they want, hate what, what should the students to learn, to keep pace with The Times, to ensure that the lectures to help students in physical education, at the same time, still can feel physical education is a kind of fun, let the students in physical education, cultivation of sports in the student life gradually.

To improve the school's teaching environment. Sports discipline is more special, more strict to the requirement of venues and equipment, especially the sports teaching in colleges and universities, for space and equipment as well as school teachers resources equipped with had high requirements, and indispensable, so to speak, even if the PE teacher again good, without good enough equipment and qualified field support, still cannot normal to carry out the sports teaching [6].So universities should first solve the problem of hardware, after all, when the money in place after the hardware problems may be better than personnel problems.

Strengthening the teachingmode of physical education and relevant innovation. As to the teaching of sports-related innovation that should not be confined to the framework of physical education to build respect, but also for the necessary innovations in teaching mode. For the construction of physical education teaching framework, it should be undertaken as a basis for 
physical education, in this context, the system of global scientific framework together, construct; and ensure basic teaching purposes at the same time, we should also do this adding different style characteristics, such as setting some of the more unusual sports items, such as billiards, bowling and rock climbing and off-road activities such obstacles; for innovative teaching patterns, it is the traditional advantages and disadvantages to first sports in colleges conducted What analysis, clear the students who want to hate what students should go to learn anything, to ensure that course content with the times [4], to help students during physical education can also feel physical education is a pleasure, let students towards Physical feel good, gradually develop sports in student life in the position occupied.

Qualitative evaluation and quantitative evaluation of the combination of teaching mode.Quantitative Evaluation of Physical Education Teaching Evaluation make scientific, standardized, quantitative evaluation has been dominant in College Physical Education Teaching Evaluation. But sports teaching is a complex process of education, sports teaching goal is to enable students to get physically and mentally healthy development, in the evaluation of students' sports learning, not only to consider the improvement of physical fitness and motor skills acquisition, but also to students psychological harmonious development as the test indicators, including many non-intelligence factors in it, such as student interest, feelings, attitudes, and these indicators rely on quantitative evaluation is difficult to quantify, simply undetectable [5]. If you ignore these aspects, physical education teaching evaluation will be one-sided. The qualitative assessment is applicable to the evaluation of non-quantitative indicators, with the generalization of education comments on all aspects of students' progress will be considered to meet the dimensions of the guiding ideology of health first detected settings. Follow sports and health education of the concept of paradigm transformation must be qualitative evaluation and quantitative evaluation of organically combined, more comprehensive and truly reflect student learning sports and health.

Teaching mode importance of teaching students in status. Students are learning the subject, should also become the main teaching mode. Teachers play a leading role in the student's learning process. Students' knowledge is evaluated with a certain group, they can actually participate in physical education teaching evaluation activities, and can make for themselves and others more objective analysis. Set up to promote students' overall development mode system, it is necessary to change the status of a single subject teaching, teaching in both embody have physical education teachers, there are other teachers [6]; both parents have student groups, the establishment of teacher-student interaction, teachers responsible for students positive complete teaching system, so that teaching to become teachers, students, parents and other body to participate in the interactive activities, embody the "interactive teaching subjects."

Fitness sports and lifelong physical education model.Implementation of Happy Sports and Fitness Sports and Lifelong Physical, will "be me" into "I want to learn." School physical education in the past cannot help but make some students appear frustration, which often form the students awareness of fitness and diet have an extremely negative impact. Set sports courses to try to avoid this phenomenon, so that students in physical education imperceptibly receive health and happiness education. Our school sports with a new look to usher in the 21st century, physical education and health classes renamed the sport, marking China's reform and development of sports in the school entered a new historical stage. School sports must establish a "health first" guiding ideology is being accepted. In the evaluation of the student's body was found, there are always some students' physical fitness is low [7]. As the general student teaching schedule, it is bound to make this part of the students involved in the process of frustration generated by the physical exercise. Therefore, it is necessary to focus this part of student teaching. Poor physical fitness for students, lack of knowledge of the basic theory of sports situation, targeted teaching, so that students learn in a given period of weight control, enhance physical fitness method, and taught skills standards, so that most of the students in the study of non-compliance [6]. After some time, not only standard pass, and can achieve good results. These students will gradually catch up on so like to participate in physical activity, and establish a good confidence in the fitness process, find the pleasure to participate in sports. 
Teaching mode importance of the evaluation of student life sports consciousness formedOne of the most fundamental tasks of college physical education is to develop students' lifelong physical ability, including physical fitness and athletic ability, exercise ability, sports and entertainment capabilities, ability to enjoy sports, these are college students into the community to exercise the necessary autonomy condition. Improve students' consciousness of their own health, will participate in sports activities passive behavior into conscious behavior, to develop good health behaviors and lifestyles, as a new era of quasi-builders and successors of the requirements, it is the teaching of college sports main target [7]. Therefore, college sports practitioners to reflect on the past traditional evaluation system, dilute the screening and selection capabilities, using incentives, strengthening students' deep understanding of the value of Physical Education, the physical exercise habits into Students real mosaic of real life. Especially for poor students physical fitness to discover them bright spot, timely feedback to their sport included in the rate of progress of learning outcomes assessment within Work. In the evaluation should examine the formation of students 'lifelong sports consciousness and development, so that physical education can affect students' future evaluation exercise will [7].

\section{Conclusion}

Institutions of higher education is to develop all-round development of all types of qualified personnel important base of China's socialist modernization drive college students a valuable asset and the backbone, as an important part of the education system, the internal optimization of physical education and implementation of initiatives to carry out the study, the practical relations to the full flowering of education effect. College Physical Education in this important part of the teaching mode, and scientific and comprehensive teaching philosophy there is a certain distance. Therefore, based on reforming the existing teaching mode, to establish a more scientific, teacher-student interaction, physical health education teaching model concept will be the future of sports teaching, which will help improve students' enthusiasm and interaction to further promote quality education, to better reflect the health of the first concept of education, and has important practical significance and strategic significance for the lifelong sports building.

\section{References}

[1] Zh. Wang and C. Di, Talk about development, theorists of college physical education, 2006.pp.85-92.

[2] X.P. Lu,On the harmonious development of university sports, The Guangxi College of Education, 2011, pp.53-56.

[3]Ch.T. Jin and Y.F. Chen,The Major in Introspect University Physical Education Quality Evaluation System, Shandong Institute of Physical Education, 2007,pp.43-47.

[4] H.M. Wang,The sports teaching theory, Beijing: Higher Education Press, 2008, pp.45-47.

[5] J.Ch.Chen,The implementation of lifelong physical education university research model, Shanghai Institute of Physical Education, 2013.pp.34-38.

[6] F.T. Huang,Health Education Course, Shanghai: East China Normal University Press, 1992, pp.114-118.

[7] Y.T.Liu, College PE teaching model implementation options, Xi'an Institute of Physical Education, 2012.pp.84-88. 